\title{
Analysis of an Elliptical Edge-Feed Microstrip Patch Antenna simulated at $800 \mathrm{MHz}$
}

\author{
R.P. Singh \\ Department of Physics \\ L. B. S. M. College \\ Jamshedpur, India
}

\author{
Md. Tufail Ahmad, PhD \\ Department of Physics \\ Karim City College \\ Jamshedpur, India
}

\begin{abstract}
In this paper the Elliptical Edge feed patch MPA (EE-MPA) has been synthesized and analyzed. It consists of a rotated elliptical patch which is feed by a microstrip line on a dielectric substrate. It has the advantage of using a single microstrip feed connected to the edge of the patch, at $45^{\circ}$ to the axes of the ellipse. EE-MPA has been designed to operate at $800 \mathrm{MHz}$. Obtained characteristics behavior of the antenna such as input impedance, reflection coefficient, gain, directivity, VSWR, axial ratio, radiation pattern and electric field has been presented in detail.

It is found that antenna radiates best in pure elliptical polarization at resonating frequency of $802.7 \mathrm{MHz}$, providing bandwidth of $13.8 \mathrm{MHz}$ and return loss obtained is about -40.42 $\mathrm{dB}$. The peak gain of antenna is $7.129 \mathrm{dBi}$ at resonating frequency and has VSWR value of 1.109. Thus, EE-MP has been designed in a way that it finds its suitability to act in communication band of microwave spectrum range.
\end{abstract}

\section{Keywords}

Microstrip Patch Antenna, Elliptical Edge Feed, Microwave Spectrum, Bandwidth, Gain, VSWR, Radiation Pattern, Axial Ration, Directivity

\section{INTRODUCTION}

Microstrip Patch Antenna is one of the most popular antenna among the antenna designers. All the credit for this goes to circuit board technology which has made the synthesis of MPA very simple and easy. Micro-strip antennas are very versatile in terms of resonant frequency, polarization pattern and impedance. All this depends upon the selection of patch shape and mode. One of the most important advantage of using a MPA is that; it is simple to construct and in very cost effective manner.

MPA is fabricated by etching method, the antenna element pattern is etched in metal layer, bonded to an insulating dielectric substrate. A continuous metal layer is attached on the opposite side of the substrate which act as the ground plane of the antenna system. Common micro-strip antenna shapes are square, rectangle, circle and ellipse.

This paper has four sections. Section 1 is introduction to research work, Section 2 give detail about the design and implementation work. Design parameter of EE-MPA has been presented in tabular form. Section 3 details the most important phase of this research work, antenna has been modeled and simulated on simulation software. Obtained results is sufficient to support its suitability in microwave wireless communication systems and finally, conclusion and obtained result has been presented in section 4 .

\section{ANTENNA DESIGN}

In this section; design, specification parameters of Elliptical Edge Feed Microstrip Patch Antenna (EE-MPA) at $800 \mathrm{MHz}$ has been presented. Rogers RT Duroid $5880^{\mathrm{TM}}$ of dielectric constant 2.2 and height $1.575 \mathrm{~mm}$ has been used as substrate in MPA antenna design. Antenna design and specification parameters have been shown in Figure 1.3D View of simulated EE-MPA is shown in Figure 2. The antenna is feed with a waveguide port at the end of a Microstrip line. The elliptical patch is feed with a single Microstrip line at $45^{\circ}$ to the axes of the ellipse. Table I shows the design specification of EE-MPA.

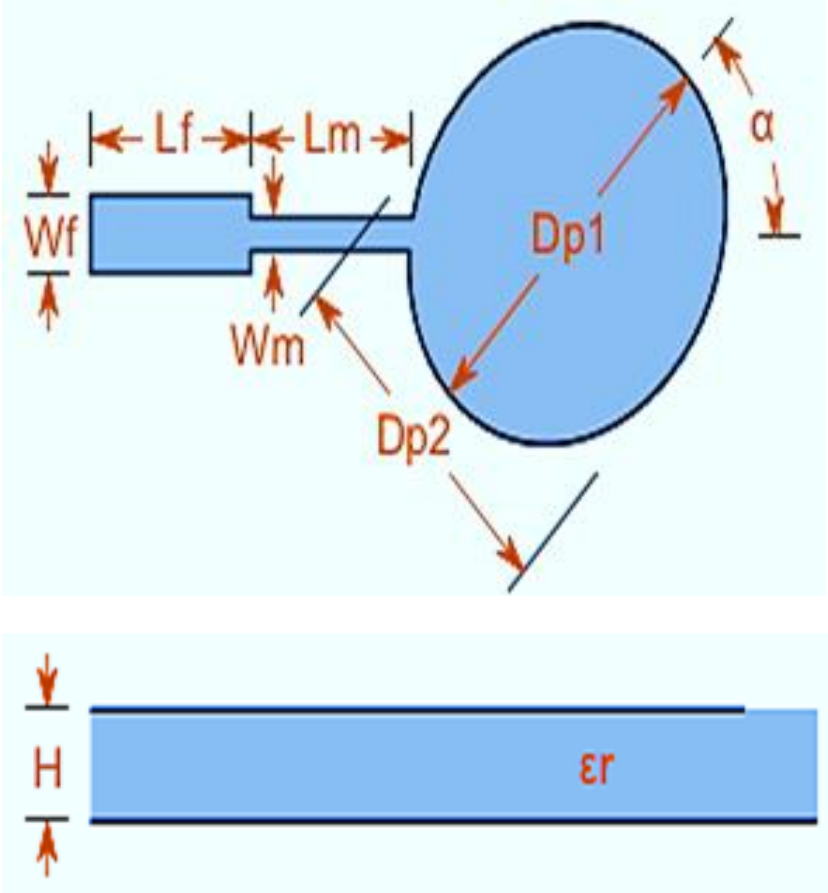

Fig 1: Deign \& Specification Parameters of EE-MPA 


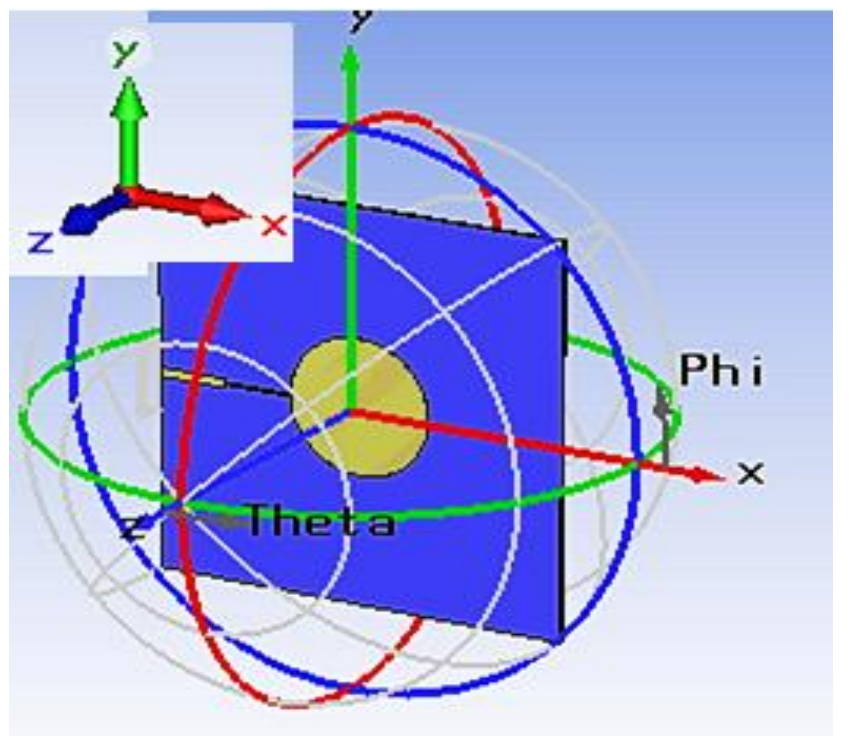

Fig 2: 3D View of Simulated EE-MPA

Table I Antenna Design Specification of EE-MPA

\begin{tabular}{|l|l|l|l|l|}
\hline $\begin{array}{l}\text { S. } \\
\text { No }\end{array}$ & $\begin{array}{l}\text { Design } \\
\text { Specification }\end{array}$ & Symbol & Value & Unit \\
\hline 1. & Center Frequency & fo & 800 & $\mathrm{MHz}$ \\
\hline 2. & Input Resistance & Rin & 50 & $\Omega$ \\
\hline 3. & Patch Diameter & Dp1 & 146.2 & $\mathrm{~mm}$ \\
\hline 4. & Patch Diameter & $\mathrm{Dp} 2$ & 144.1 & $\mathrm{~mm}$ \\
\hline 5. & Rotation Angle & $\alpha$ & -45 & degree \\
\hline 4. & $\begin{array}{l}\text { Matching Line } \\
\text { Length }\end{array}$ & $\mathrm{Lm}$ & 69.08 & $\mathrm{~mm}$ \\
\hline 5. & $\begin{array}{l}\text { Matching Line } \\
\text { Width }\end{array}$ & $\mathrm{Wm}$ & 2.594 & $\mathrm{~mm}$ \\
\hline 6. & Feed Line Length & Lf & 68.49 & $\mathrm{~mm}$ \\
\hline 7. & Feed Line Width & Wf & 9.783 & $\mathrm{~mm}$ \\
\hline 8. & $\begin{array}{l}\text { Length of Antenna } \\
\text { (X-axis) }\end{array}$ & & 355.3 & $\mathrm{~mm}$ \\
\hline 9. & $\begin{array}{l}\text { Width of Antenna } \\
\text { (Y-axis) }\end{array}$ & & 145.2 & $\mathrm{~mm}$ \\
\hline 10. & Height (Z-axis) & & 3.175 & $\mathrm{~mm}$ \\
\hline
\end{tabular}

\section{SIMULATIONS}

In this section, analysis of designed antenna has been performed using Antenna Magus and CST Studio Suite. Antenna characteristic parameters has been analyzed and presented in detail.

\subsection{Antenna Input Impedance}

Input Impedance Vs Operating Frequency of the antenna has been shown in Figure 3. It is observed that at resonating frequency only real value for input impedance exists for synthesized Elliptical Edge feed MPA. It has been found that the real value of impedances is $55.89 \Omega$ at the resonating frequency, 802.7 MHz.

\subsection{Antenna Reflection Coefficient}

The power reflected from the antenna is given by the parameter $\mathrm{S}$ which is also known as the reflection coefficient or the return loss. Figure 4 presents the Return loss curve of the designed Elliptical Edge feed MPA.

Figure 4 implies that the MPA radiates best between 794.3 $\mathrm{MHz}$ to $808.1 \mathrm{MHz}$, providing a bandwidth of $13.8 \mathrm{MHz}$, where $\mathrm{S} 11$ is $-10 \mathrm{~dB}$ or less. Further, at the resonating frequency of $802.7 \mathrm{MHz}$, return loss obtained is about -40.42 $\mathrm{dB}$.

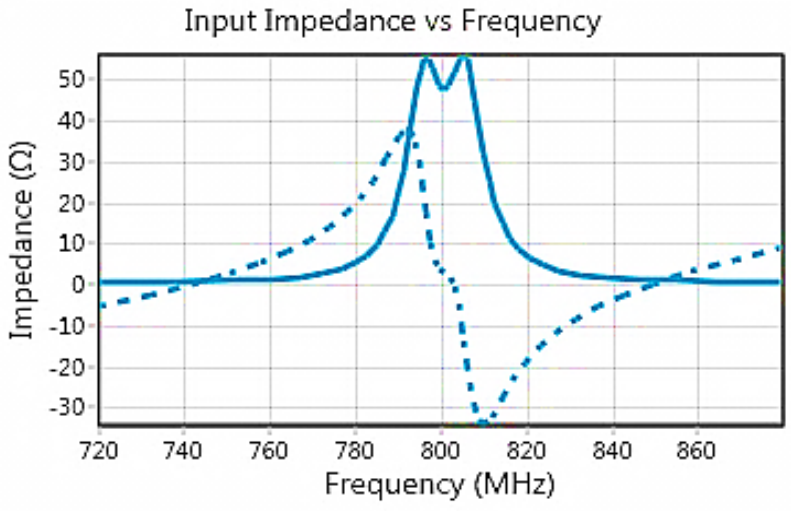

Fig 3: Input Impedance Vs Frequency Plot of EE-MPA

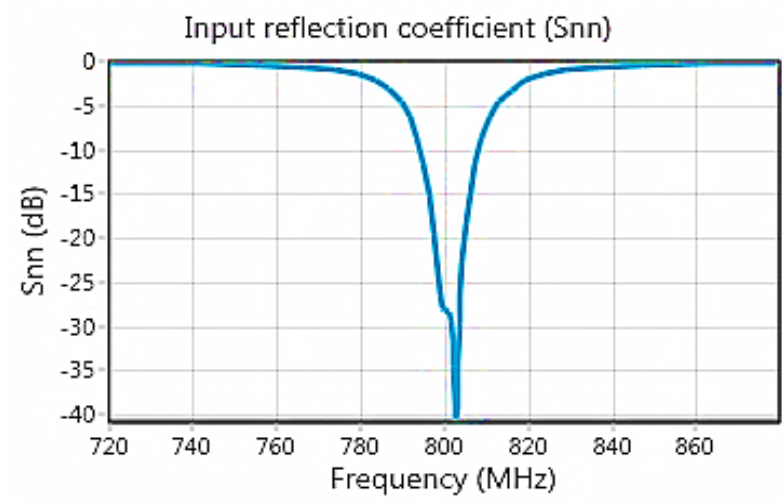

Fig 4: Return Loss Curve of EE-MPA obtained in Antenna Magus

\subsection{Gain}

Power transmitted in the direction of the peak radiation by the synthesized antenna to that of an isotropic antenna source is termed as gain of the synthesized antenna. Antenna gain considers the actual losses occurred in the antenna system. Figure 5 presents the normalized gain of MPA as the radiation pattern. The peak gain of antenna is $7.129 \mathrm{dBi}$ at resonating frequency.

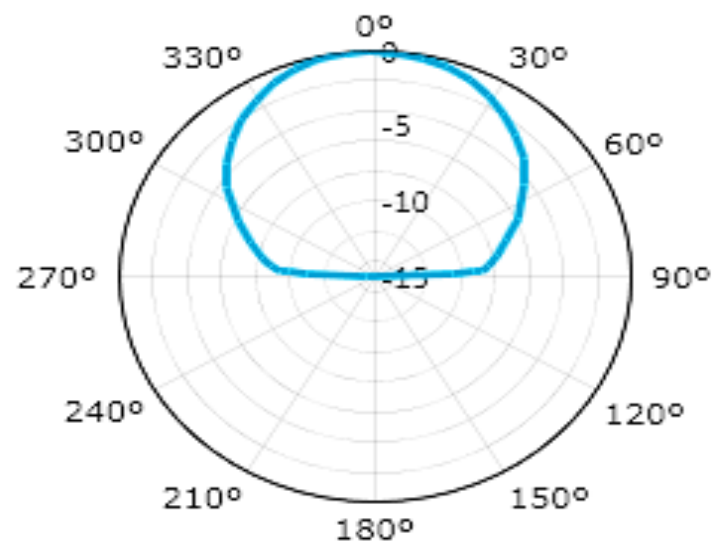

Fig 5: Normalized Gain of EE-MPA 


\subsection{VSWR}

VSWR Vs Operating Frequency of the antenna has been shown in Figure 6. It is observed that at resonating frequency synthesized MPA has small value of VSWR ranging between 1 and 1.5. It is found from the figure that Antenna has VSWR value of 1.019 at the resonating frequency of $802.7 \mathrm{MHz}$.

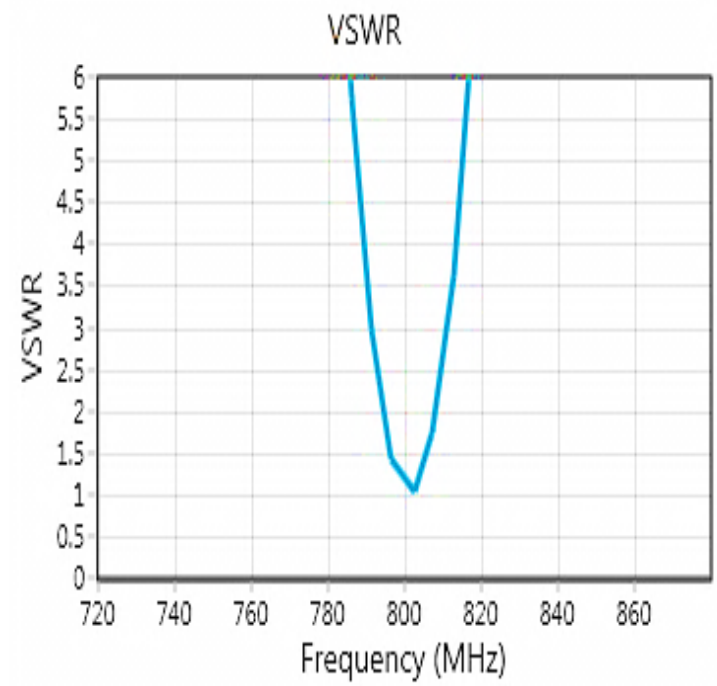

Fig 6: VSWR Vs Frequency of EE-MPA

\subsection{Axial Ratio}

For pure elliptical polarization the axial ratio is $0 \mathrm{~dB}$ and for linear polarization the axial ratio is $\infty$. From the $3 \mathrm{D}$ result shown in Figure 7, observation is made about the polarization of MPA. It is found that the antenna will propagate pure elliptical polarization between $794.3 \mathrm{MHz}$ to $808.1 \mathrm{GHz}$.

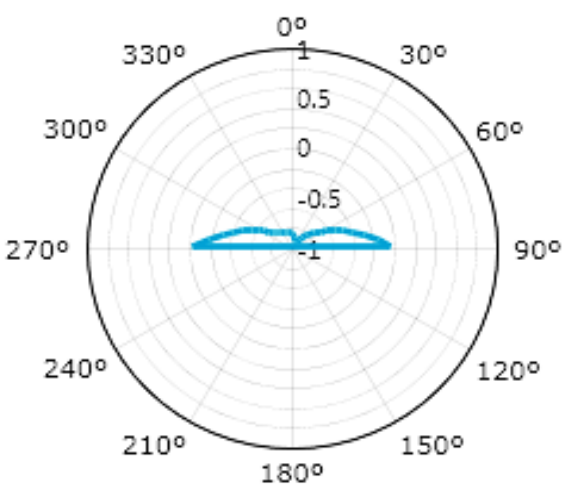

Fig 7: Axial Ratio of EE-MPA

\subsection{Antenna Directivity}

Figure 8 shows the directivity of Elliptical Edge Feed MPA. Absolute value of directivity is found to be $8.176 \mathrm{dBi}$.

\subsection{Radiation Pattern}

Radiation patterns have been presented in elevation angle $(\theta$ degree) and azimuth angle ( $\varphi$-angle). Figure 9 is the elevation pattern, which represents the plot of the radiation pattern as a function of the angle measured off the z-axis (for a fixed azimuth angle). Observing Figure 9, it is deduced that the radiation pattern is minimum at 0 and 180 degrees and becomes maximum broadside to the antenna (90 degrees off the z-axis). Figure 10 shows the Radiation Pattern of Elliptical Edge Feed MPA at Elevation Angle Phase. The radiation pattern shown in Figure 11 is the azimuthal plot. It is a function of the azimuthal angle for a fixed polar angle ( 90 degrees off the z-axis in this case).

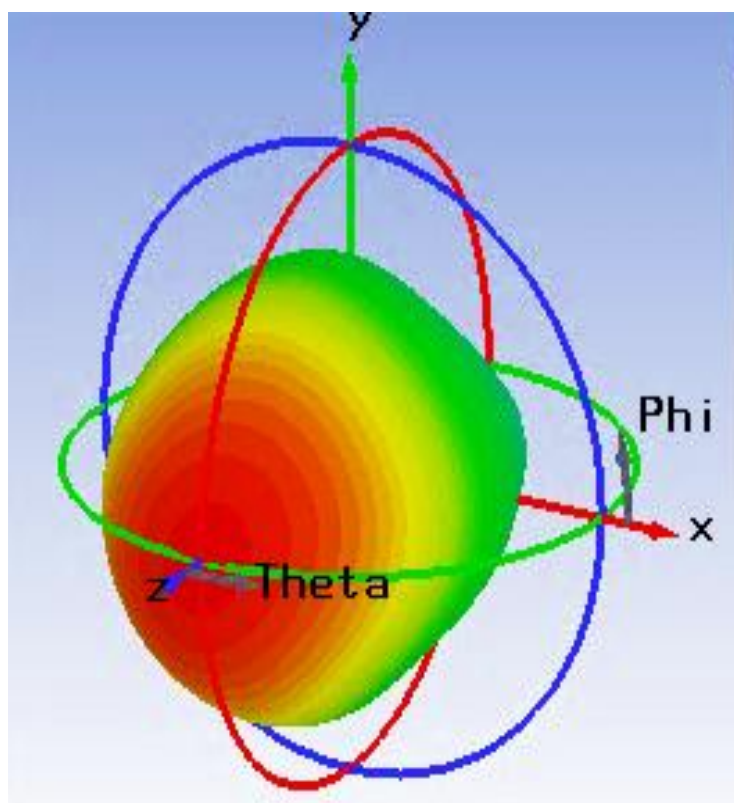

\begin{tabular}{ll}
\hline Type & Farfield \\
Approximation & enabled $(k R \gg 1)$ \\
Monitor & farfield $(\mathrm{f}=800)[1]$ \\
Component & Abs \\
Output & Gain \\
Frequency & 800 \\
Rad. effic. & $-0.1689 \mathrm{~dB}$ \\
Tot. effic. & $-1.104 \mathrm{~dB}$ \\
Gain & $8.176 \mathrm{~dB}$ \\
\hline
\end{tabular}

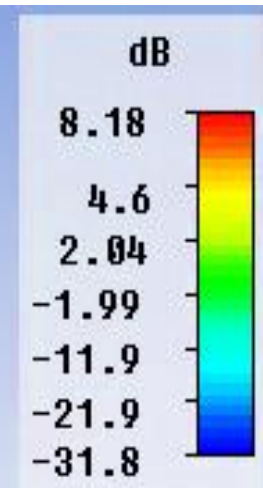

Fig 8: Directivity of EE-MPA 


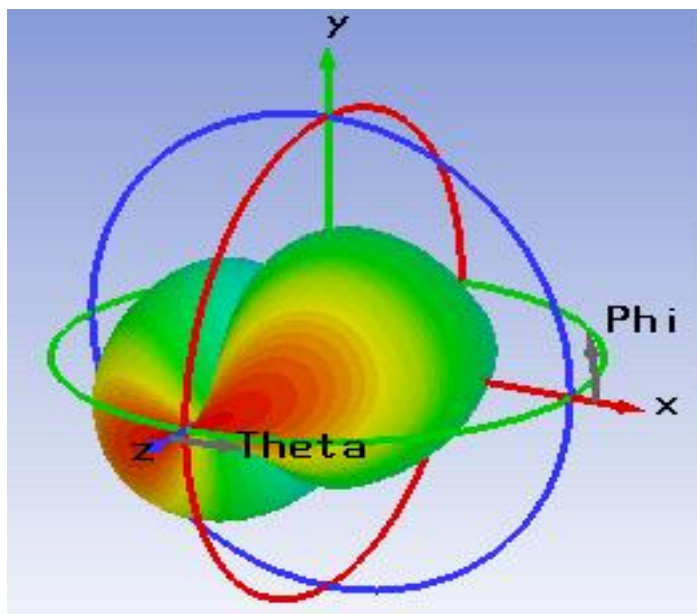

$\begin{array}{ll}\begin{array}{ll}\text { Type } \\ \text { Approximation }\end{array} & \begin{array}{l}\text { Farfield } \\ \text { enabled }(\mathrm{kR} \Rightarrow>1) \\ \text { Monitor }\end{array} \\ \text { far field }(\mathrm{f}=800)[1] \\ \text { Component } & \text { Theta } \\ \text { Output } & \text { Gain } \\ \text { Frequency } & 800 \\ \text { Rad. effic. } & -0.1689 \mathrm{~dB} \\ \text { Tot. effic. } & -1.104 \mathrm{~dB} \\ \text { Gain(Abs) } & 8.176 \mathrm{~dB} \\ \text { Gain(Theta) } & 8.043 \mathrm{~dB}\end{array}$

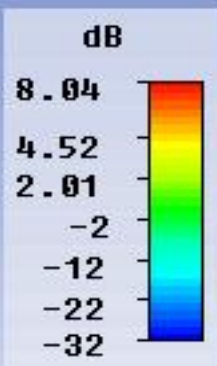

Fig 9: Radiation Pattern of EE-MPA at Elevation Angle
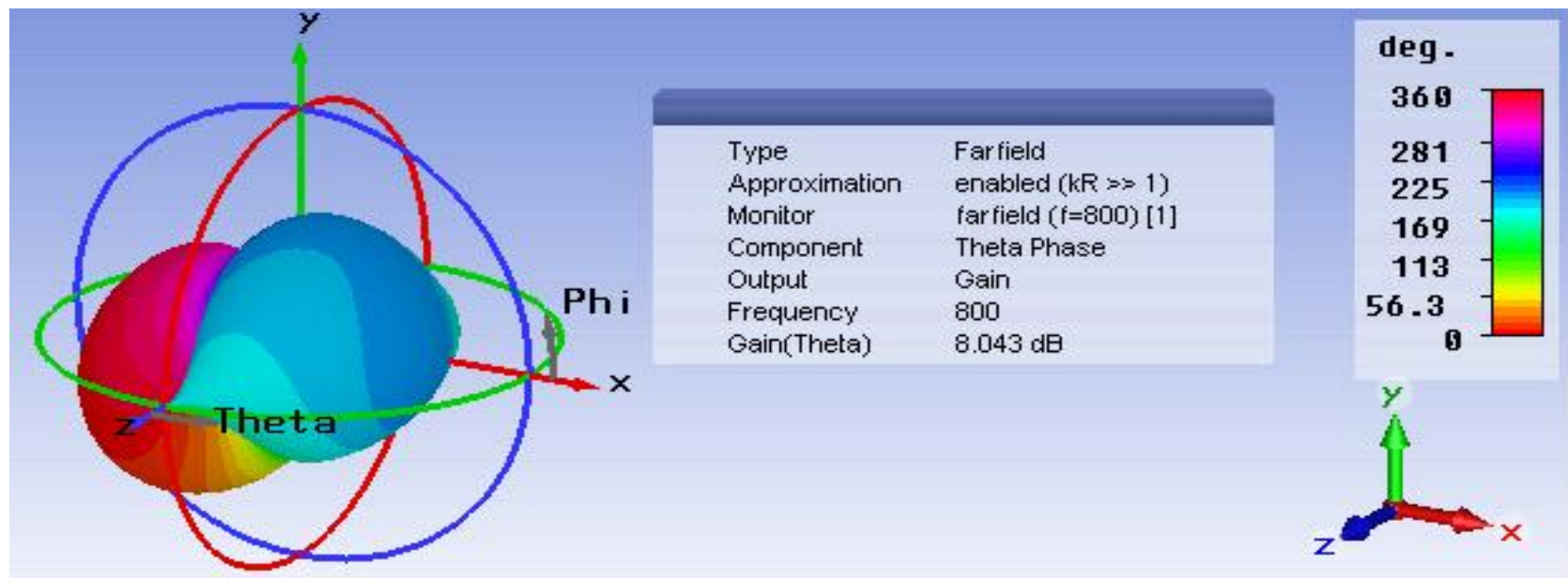

Fig 10: Radiation Pattern of EE-MPA at Elevation Angle Phase

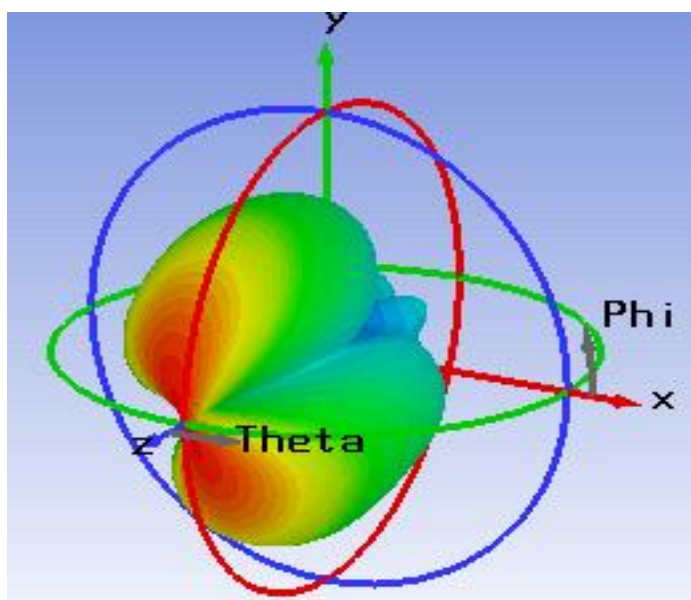

$\begin{array}{ll}\text { Type } & \text { Farfield } \\ \text { Approximation } & \text { enabled }(\mathrm{kR} \Rightarrow 1) \\ \text { Monitor } & \text { far field }(\mathrm{f}=800)[1] \\ \text { Component } & \text { Phi } \\ \text { Output } & \text { Gain } \\ \text { Frequency } & 800 \\ \text { Rad. effic. } & -0.1689 \mathrm{~dB} \\ \text { Tot. effic. } & -1.104 \mathrm{~dB} \\ \text { Gain(Abs) } & 8.176 \mathrm{~dB} \\ \text { Gain(Phi) } & 8.043 \mathrm{~dB}\end{array}$

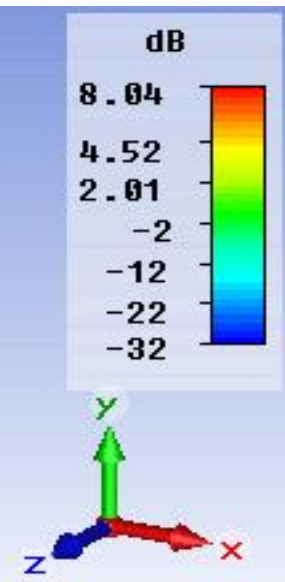

\section{CONCLUSION}

Synthesis and analysis of EE-MPA has been achieved successfully. For an Elliptical Edge Feed Microstrip Patch

\section{Fig 11: Radiation Pattern of EE-MPA at Azimuth Angle}

Antenna, resonant frequency can be increased by increasing the patch's diameter, but ratio of major to minor axes should be kept constant. Bandwidth can be increased by increasing the substrate height or decreasing the relative permittivity of 
substrate. During the analysis, it is found that antenna radiates in pure elliptical polarization between $794.3 \mathrm{MHz}$ to 808.1 $\mathrm{GHz}$, providing a bandwidth of $13.8 \mathrm{MHz}$, where $\mathrm{S} 11$ is $-10 \mathrm{~dB}$ or less. Further, at the resonating frequency of $802.7 \mathrm{MHz}$, return loss obtained is about $-40.42 \mathrm{~dB}$. The peak gain of antenna is $7.129 \mathrm{dBi}$ at resonating frequency and has VSWR value of 1.109. Thus, the designed antenna is a suitable candidate for wireless communication at $800 \mathrm{MHz}$.

\section{ACKNOWLEDGMENT}

This research work has been completed as a part of thesis work entitled "Study of Broadband Microstrip Patch Antenna". Author thanks members and technical staff at Department of Physics, C. M. Science College, Darbhanga, Bihar, India for providing essential requirements and assistance in completing this research work in time.

\section{REFERENCES}

[1] Yoonjae Lee and Yang Hao, "Characterization of microstrip patch antennas on meta-material Substrates loaded with complementary split-ring Resonators", Wiley Periodicals, Inc. Microwave Opt. Technol. Lett. 50, pp. 2131-2135, 2008.
[2] Abumazwed,A.,Sebak,A.R., "Compact dielectric resonator antenna for broadband applications (5.2/5.8GHz)\|, European Conference on Antennas and Propagation", EuCAP 2009, Proceedings , art. no. 5067658, pp. 433-436, 2009.

[3] B. Jyothi, B.T.P Madhav, V.V.S. Murthy, P. Syam Sundar VGKM Pisipati, "Comparative Analysis of Micro-strip Co-axial Feed, Inset Feed and Edge Feed Antenna operating at fixed frequency", International journal of scientific and research publications, Vol. 2, Issue 2, February 2012.

[4] Neeraj Kumar, A. K. Thakur, Arvind Kumar, "Synthesis and Analysis of an Edge Feed and Planar Array Microstrip Patch Antenna at $1.8 \mathrm{GHz}$ ", International Journal of Engineering, Research and Technology, pp. 1617-1622, vol. 2, issue 9, Sep. 2013, ISSN: 2278-0181.

[5] S. N. Singh, Neeraj Kumar, A. K. Thakur "A Multiple Input Multiple Output Dielectric Resonator Patched Antenna for Wireless System Applications", 8th International Conference on Microwaves, Antenna and Remote Sensing, Conference Proc., pp. no. 466-469, 11th 15th Dec. 2012, Jodhpur, Rajasthan. 